
Piter, 987.

6. Moock, K. (2009). Action Script 3.0 for Flash.

7. Rybalko, O. A. (2011). Create a task using the text fields in the program Adobe Flash CS3 Professinal [Sozdanie zadaniy s ispolzovaniem tekstovyh poley v programme Adobe Flash CS3 Professinal]. Computer in school and family, 2, 25-29.
8. Rybalko, O. A. (2008). Creation tests for younger

students in the program Macromedia Flash Professional 8 [Sozdanie testov dlya mladshih shkolnikov $\mathrm{v}$ programme Macromedia Flash Professional 8]. Computer in school and family, 4, 17-19.

9. Plankina, D. Yu. (2013). The use of magic squares for the development of the ability to reason [Ispolzovanie magicheskih kvadratov dly razvitiya umeniya rassuzhdat]. Primary school, 11, 66-70.

Рекомендовано до публікаиії д-р пед. наук Бурда М. I. Дата надходження рукопису 28.01.2015

Рыбалко Ольга Алексеевна, преподаватель, Прилукский гуманитарно-педагогический коллледж им. И. Я.Франка, ул. Порбеды, 170, г. Прилуки, Черниговской обл., Украина, 17500

Email: RybalkoOlga2009@rambler.ru

\author{
УДК 378.147.091.33-021.464 \\ DOI: 10.15587/2313-8416.2015.37480
}

\title{
САМОСТОЯТЕЛЬНАЯ РАБОТА СТУДЕНТОВ КАК ПЕДАГОГИЧЕСКАЯ ПРОБЛЕМА
}

\author{
(C) Е. А. Рощупкина
}

Цель данной статьи - описать самостоятельную работу студентов как педагогическую проблему, а именно: определить место самостоятельной работы в системе дидактических понятий, раскрыть сущность самостоятельной работь студентов в педагогике, психологии и методике преподавания иностранных языков, в том числе русского языка как иностранного, проанализировать аспекты самостоятельной работьл

Ключевые слова: самостоятельная работа, самостоятельная деятельность, автономия, сущность, аспект, иностранные студенты, довузовский этап

The purpose of this article - to describe self-independent work of students as a pedagogical problem, namely: to define a place of independent work in system of didactic concepts, to explain essence of self-independent work of students in pedagogics, psychology and a methodology of teaching the foreign languages, including Russian as foreign, to analyze aspects of self-independent work

Keywords: self-independent work, self-independent activity, autonomy, essence, aspect, foreign students, preuniversity stage

\section{1. Введение}

На этапе интеграции образования в единое европейское научное пространство возрастают требования к уровню знаний студентов. Одним из важных условий обеспечения высокого качества подготовки будущих специалистов, готовых к постоянному профессиональному росту, способных учиться на протяжении всей жизни, является усиление роли самостоятельной работы (СР).

\section{2. Постановка проблемы}

Увеличение объема самостоятельной работы, доля которой при кредитно-модульном обучении составляет более $40 \%$, повышение ее значения влечет за собой реорганизацию учебного процесса в вузе, создание условий для развития и самореализации каждого студента и прежде всего для формирования у него умения учиться самостоятельно. В связи с этим назрела необходимость изменения содержания $\mathrm{CP}$, дальнейшего изучения ее различных аспектов и подходов к данной проблеме, в том числе при обучении иностранных студентов на довузовском этапе - подготовительном факультете.

\section{3. Литературный обзор}

В научной литературе рассматриваются различные аспекты самостоятельной работы: общепедагогические подходы к раскрытию сущности СР студентов (М. Гарунов, В. Козаков, А. Молибог, П. Пидкасистый и др.), ее планирование и организация (Б. Есипов, И. Лернер и др.), проблемы управления и контроля (И. Андреева, К. Есипович, Л. Жарова, А. Лында и др.), значение самообразования и самоподготовки к профессио-нальной деятельности (А. Громцева, Ю. Кулюткин, Г. Сухобская и др.), механизмы развития самостоятельности и активности личности в разных видах деятельности (П. Гальперин, В. Давыдов, Е. Кабанова-Миллер и др.) и т. д. [1-12]. Отдельные частнометодические аспекты СР иностранных студентов изучают О. Отменитова, Л. Прядина, Л. Сеник и др. 
Анализ теории вопроса показал, что в дидактике нет единого понимания того, какую единицу представляет самостоятельная работа, она рассматривается как: вид познавательной деятельности (Л. Вяткин, В. Листенгартен, В. Козаков и др.), форма организации учебной деятельности (В. Граф, И. Ильясов, В. Ляудис и др.), средство вовлечения студентов в самостоятельную деятельность (М. Гарунов, И. Унт и др.), метод обучения (Ю. Бабанский, Л. Жарова и др.), прием учения (А. Усова и др.).

Самостоятельная работа исследуется применительно к изучению конкретных дисциплин, в частности, иностранных языков, где также наблюдается разнообразие мнений относительно сущности, роли, путей организации и управления самостоятельной работой студентов при обучении неродному языку. Так, по Р. Миньяр-Белоручеву самостоятельная работа трактуется как форма обучения, предусматривающая индивидуальную работу студентов в соответствии с установкой преподавателя или учебника [12]; Е. Иващик предлагает рассматривать СР как средство организации и управления коммуникативно-познавательной деятельностью обучаемых [7]; по мнению Р. Мильруд самостоятельная работа - это резерв повышения эффективности учебного процесса [11] и т. д. Вместе с тем, несмотря на то, что понятие самостоятельной работы постоянно является предметом исследования педагогов, психологов и методистов, по прежнему остается весьма актуальным глубокое изучение и анализ состояния данной проблемы в теории и практике обучения в вузе, в частности, на довузовском этапе.

\section{4. Теоретические основы изучения самостоятельной работы в ВУЗе}

Цель статьи - описать самостоятельную работу студентов как педагогическую проблему, а именно: определить место СР в системе дидактических понятий, раскрыть сущность самостоятельной работы студентов в педагогике, психологии и методике преподавания иностранных языков, проанализировать аспекты самостоятельной работы.

В научно-методической литературе последних десятилетий наблюдается смешение и даже отождествление понятий «самостоятельная работа», «самостоятельная учебная деятельность», «учебная автономия (автономность)» (Л. Трофимова, Е. Соловова, Т. Тамбовкина, Г. Голек, Л. Дикинсон и др.) [13-15]. По нашему мнению, самостоятельная работа представляет собой подсистему самостоятельной деятельности, которая, в свою очередь, является компонентом системы обучения в целом. Разграничивая понятия «самостоятельная работа»и «учебная автономия», мы рассматриваем самостоятельную работу начальным этапом автономного обучения, а формирование и развитие учебной автономии студента есть главная задача образовательного процесса в целом.

Одной из важнейших проблем самосто ятельной работы является определение ее сущности. Анализ научной литературы свидетельствует о многочисленности и многообразии толкований данного понятия. Характерной чертой всех опреде лений СР является усиление одного из ее признаков, и, в конечном счете, ни одна из дефиниций не раскрывает полностью ее сути. Наиболее полное определение самостоятельной работы с точки зрения самого субъекта, на наш взгляд, дает И. Зимняя: самостоятельная работа студента - это «целенаправленная, внутренне мотивированная, структурированная самим субъектом в совокупности выполняемых действий и корригируемая им по процессу и результату деятельность [4]», выполнение которой требует достаточно высокого уровня самосознания, самодисциплины, личной ответственности и которая доставляет удовлетворение как процесс самосовершенствования и самопознания [4].

Самостоятельная работа иностранных студентов подготовительных факультетов представляет собой многогранное явление, синтез нескольких направлений: вид учебно-познавательной деятельности; дидактическая форма совместной аудиторной и внеаудиторной учебной деятельности студента и преподавателя, которая учитывает индивидуальные способности каждого студента; средство вовлечения иностранных студентов в самостоятельную познавательную деятельность в новой для них языковой среде. Обобщив теоретический и практический опыт исследователей, мы определяем сущность СР в единстве процессуальной и содержа-тельной сторон и предлагаем понимание самостоятельной работы иностранных студентов данного этапа как высшей формы организации учебно-познавательной деятельности студентов, которая рассматривается в контексте процесса управления формированием личности специалиста и подготовки его к непрерывному профессиональному самообразованию, как внутренне мотивированной, целенаправленной деятельности, осуществляемой под опосредованным руководством преподавателя в аудиторное и внеаудиторное время с целью овладения профессиональными знаниями, умениями и навыками в процессе обучения русскому языку.

В современной дидактике педагогическая проблема самостоятельной работы в высшей школе заключается в том, чтобы в процессе самостоятельной работы сформировался не «средний» студент, а самостоятельно мыслящая личность. Это достигается путем рациональной организации СР, формирования у студентов готовности и мотивации к ее выполнению, эффективного управления, активизации, соблюдения этапности в ее (само)организации и проведении, разнообразия ее видов, обязательного (само)контроля ее результатов и т. д.

Вопросы организации самостоятельной работы обучающихся всегда находились в центре внимания ученых (А. Богоявленская, С. Скрибко и др.), которые утверждают, что формирование специалиста, обладающего фундаментальными знаниями, профессиональными умениями и навыками, опытом творческой и исследовательской деятельности по решению новых проблем, возможно при оптимальной организации процесса самообучения. К основ- 
ным условиям эффективной организации СР исследователи относят: готовность студентов к самостоятельному труду, мотив к получению знаний, систематичность организации $\mathrm{CP}$, наличие и доступность учебно-методического и справочного материала, разнообразие видов СР и постепенность их введения по степени сложности, систему регулярного контроля и самоконтроля за процессом и результатом ее выполнения, консуль-тативную помощь.

Важнейшим условием эффективной организации СР является развитие у обучаемых саморегуляции и навыков самоуправления (А. Жуков, О. Конопкин, А. Осницкий). Студент должен освоить управляющие функции преподавания: ему необходимо научиться планировать, организовывать, анализировать, оценивать собственные учебные действия. Студент должен, зная разные способы приобретения знаний, уметь выбирать из них наиболее эффективные в данной учебной ситуации.

Формами организации СР студентов могут быть как индивидуальная работа, так и работа в парах и подгруппах. Наиболее эффективными формами вовлечения студентов в разнообразную самостоятельную деятельность являются предметные кружки, тематические вечера, конкурсы на знание предмета, учебные экскурсии и т. п.

Задача организации СР в вузе поднимает ряд вопросов, относящихся к готовности самого студента как субъекта этой формы деятельности к ее осуществлению. Выделяют коммуникативную и психологическую готовность (А. Капаева). Составляющими коммуникативной готовности являются лингвистическая (наличие достаточного для включения в процесс речевой деятельности лексикограмматического минимума) и методическая (владение способами и приемами самостоятельной деятельности, умение ориентироваться в этой деятельности, знание особенностей ее осуществления, наличие необходимого опыта по распознаванию, воспроизведению и самостоятельному использованию языкового материала в процессе общения на иностранном языке). Психологическую готовность составляют мотивационная (желание и стремление выполнить действие самостоятельно) и интеллектуальная (владение необходимыми и достаточно развитыми мыслительными операциями: сравнение, анализ, синтез и др.).

Практика языковой подготовки иностранных студентов показывает, что многие из них не готовы стать субъектами учебного процесса, что, в свою очередь, не позволяет им быстро и активно включиться в учебный процесс вузов. Все это свидетельствует об актуальности и важности формирования у студентов-иностранцев готовности к рациональному и эффективному осуществлению самостоятельной работы.

Проблема готовности студента к СР перерастает в проблему предварительного формирования и последующего повышения его учебной мотивации (Е. Ильин, А. Маркова и др.). Мотивацию самостоятельной работы мы рассматриваем как сложную, многоуровневую систему и понимаем ее как процесс, в результате которого самостоятельная деятельность приобретает для студента личностный смысл, создает устойчивость интереса к ней, превращая заданные извне цели в его внутренние потребности. Различают две группы мотивов учебной деятельности: внешние и внутренние. Внешняя мотивация самостоятельной работы иностранных студентов проявляется в желании достичь успехов по учебному предмету с целью повышения их личностного авторитета в группе; в осознании того, что успех дальнейшей профессиональной подготовки в вузе зависит от результатов обучения на подготовительном факультете. Внутренняя мотивация связана с познавательной деятельностью студентов, целью которой является получение знаний, приобретение необходимых умений и навыков. В процессе организации СР важно учитывать следующие условия успешного формирования внутренней мотивации: свободу студента в выборе вида самостоятельной работы, стратегии ее выполнения; использование внешнего контроля как средства информирования студента об успешности его самостоятельной работы; значимость результатов для студента; пробуждение интереса к обучению.

Формирование мотивации у иностранных студентов необходимо начинать уже на подготовительном факультете, поддерживать и развивать внутренние мотивы на последующих этапах обучения в вузе с тем, чтобы в дальнейшем они смогли самостоятельно мотивировать свою учебную и профессиональную деятельность. Понимание студентами-иностранцами того, что от уровня владения русским языком во многом зависит качество их профессиональной подготовки, порождает потребность в самостоятельном приобретении новых дополнительных знаний, умений и навыков и, как следствие, повышает эффективность их обучения в вузе. Следовательно, мотивация самостоятельной учебной деятельности в процессе овладения русским языком формируется у иностранных студентов в результате динамики внутренних познавательных мотивов, активизации внешних мотивов и сближения внешней и внутренней мотивации.

Одной из важных проблем самостоятельной работы студентов является самостоятельное управление своей познавательной деятельностью (К. Есипович, Н. Иголкина, В. Якунин и др.). Организованное управление и сознательное самоуправление являются важнейшим фактором повышения эффективности и качества обучения.

В психолого-педагогической литературе подчеркивается необходимость перехода от непосредственного (прямого) к опосредованному (косвенному) управлению, а также изменения степени его жесткости: от жесткого к максимально гибкому. В условиях подготовительных факультетов по мере приобретения студентами-иностранцами необходимых умений и навыков жесткое управление постепенно должно уступать место полужесткому, а затем приобретать опосредованный характер. Таким 
образом, гибкость управления самостоятельной работой иностранных студентов становится отдельной педагогической и методической проблемой ее организации.

Проблема активизации самостоятельной работы является одной из главных (Р. Низамов, Т. Шамова, Г. Щукина и др.). Под активизацией самостоятельной работы студентов понимают целенаправленную совместную деятельность преподавателя и студентов, предполагающую совершенствование содержания, форм, методов, приемов познавательной деятельности с целью формирования положительной учебной мотивации, повышения профессиональной компетенции будущих специалистов на основе развития таких личностных качеств обучающихся, как активность, творчество, самостоятельность. Активизация самостоятельной работы студентов в учебном процессе - это важное условие совершенствования их знаний. Она способствует формированию умений и навыков применять полученные знания на практике, ведет к глубокому и прочному их усвоению, приводит к изменению позиции студента в учебном процессе, превращая его в активного субъекта обучения в вузах и возможна при условии овладения студентами всеми компонентами самообразовательной деятельности (мотивационным, целеполагающим, организационным, процессуальным, контролирующим и оценочным). Педагогическая практика использует различные пути активизации СР, основными среди которых есть: проблемное обучение, разнообразие форм, методов, средств обучения, стимулирующих активность и самостоятельность обучающихся.

Обязательным условием, обеспечивающим эффективность СР, является соблюдение этапности в eе самоорганизации и проведении. При этом выделяют этап самонастройки или ориентировочную часть: целеполагание, составление программы. На данном этапе студенту необходимо понять основную учебную задачу, осознать, для чего требуется изучение данного учебного материала, что конкретно он должен узнать и освоить. Очень важно определить уровень обученности и развития умений, которого должен достичь студент в процессе работы. Тем самым у него будут формироваться познавательные, учебные интересы и положительная мотивация. Все это является необходимым условием включения студентов в предстоящую активную СР. Вторым этапом является самоорганизация или этап исполнения, включающий планирование, выбор средств и источников, реализацию, применение знаний, фиксирование результатов. На данном этапе происходит усвоение и отработка учебного материала до того уровня, который предусмотрен в ориентировочной части. Наконец, третий - это этап самоанализа и самоконтроля, представляющий собой самооценку и самокорректировку усвоенных и отработанных знаний и умений.

Многообразие видов СР студентов в зависимости от конкретных дидактических целей и задач, содержания изучаемого материала, характера познавательной деятельности, количества обучаю- щихся, источника знаний, степени самостоятельности обучающихся позволяет интенсифицировать и повысить эффективность самостоятельной работы. Главными критериями выбора вида самостоятельной работы являются: общая цель и задачи содержания образования, дидактические цели, содержание учебного материала, индивидуальные особенности и способности, подготовленность студентов к данному виду СР, уровень подготовки преподавателя и его мастерства.

Вопросы самоконтроля в педагогике и психологии находят отражение во многих исследованиях (Б. Белькевич, М. Брейгина, Н. Змиевская и др.). Суть самоконтроля - выявить уровень усвоения студентами знаний, сформированности у них умений и навыков, соответствующих образовательным требованиям по учебной дисциплине и отраженных в программе. Исследователи едины во мнении, что «контроль результатов усвоения материала в условиях СР может быть эффективным только в том случае, если четко определены цели и необходимые уровни усвоения, уровни обученности, которые должны быть достигнуты в результате обучения [2]». Среди функций самоконтроля и контроля традиционно выделяют контролирующую, обучающую и воспитывающую. Видами проверки, в том числе и в условиях подготовительных факультетов для иностранных студентов, являются текущая, тематическая, цикловая и итоговая. Обобщив теоретический опыт исследований, педагоги выдвигают следующие требования к контролю и самоконтролю: объективность, всесторонность, систематичность, гласность, индивидуализация, дифференциация, учет специфики учебного предмета, разнообразие форм и методов [9].

\section{5. Выводы}

Таким образом, самостоятельная работа является одной из важнейших педагогических проблем в теории и практике высшей школы. В психолого-педагогической литературе накоплен значительный фонд работ, в которых ученые исследуют различные аспекты по изучению проблемы самостоятельной работы, осуществляют поиск новых решений вопросов, относящихся к ее сущности, организации, управлению, активизации, классификации видов, готовности студентов к выполнению СР и др., требующих постоянного изучения в силу как многогранности и сложности данного понятия, так и происходящих изменений в современном мире образования. В научных трудах прослеживается динамика рассмотрения СР от характеристики только ее внешней стороны до анализа единства внешней и внутренней сторон.

Самостоятельная работа иностранных студентов подготовительных факультетов рассмат-ривается как синтез нескольких направлений: вид учебнопознавательной деятельности, дидактическая форма совместной аудиторной и внеаудиторной учебной деятельности студента и преподавателя, средство вовлечения иностранных студентов в самостоятельную познавательную деятельность в новой для них 
языковой среде. Сущность СР иностранных студентов определяется нами в единстве процессуальной и содержательной сторон и понимается как внутренне мотивированная, целенаправленная деятельность, осуществляемая под опосредованным руководством преподавателя в аудиторное и внеаудиторное время с целью овладения профессиональными знаниями, умениями и навыками в процессе обучения русскому языку.

\section{Литература}

1. Богоявленская, А. Е. Педагогическое руководство самостоятельной работой и развитием познавательной самостоятельности студентов [Текст]: уч. пос. / А. Е. Богоявленская. - Тверь: Твер. гос. ун-т, 2002. - 106 с.

2. Граф, В. Основы самоорганизации учебной деятельности и самостоятельная работа студентов [Текст]: уч.-мет. пос. / В. Граф, И. И. Ильясов, В. Я. Ляудис. - М.: Изд-во Моск. ун-та, 1981. - 80 с.

3. Жуков, А. Е. Организация самостоятельной работы студентов в высшей школе. Дидактические средства, технологии, программы: монография [Текст] / А. Е. Жуков, А. В. Симоненко. - М.: ЮНИТИ-ДАНА, 2004. - 220 с.

4. Зимняя, И. А. Педагогическая психология [Текст]: учебник / И. А. Зимняя. - М. : Университетская книга, Логос, 2007. - 384 с.

5. Змиевская, Н. П. Контроль и самоконтроль в системе упражнений по обучению научному стилю речи иностранных студентов на начальном этапе [Текст] / Н. П. Змиевская, О. Г. Мирошникова // МОВА. - 2008. № 13. - C. 144-146.

6. Ильин, Е. П. Мотивация и мотивы [Текст] / Е. П. Ильин. - СПб: Питер, 2000. - 512 с.

7. Иващик, Е. А. Самостоятельная внеурочная учебная работа учащихся как средство совершенствования учебно-воспитательного процесса по иностранному языку в средней школе (нем. яз. 7 кл. ) [Текст]: автореф. дис. ... канд. пед. наук : 13.00.02 / Е. А. Иващик. - Моск. гос. пед. ин-т им. В. И. Ленина. - М., 1989. - 16 с.

8. Капаева, А. Е. О формировании готовности учащихся к самообучению иностранным языкам [Текст] / А. Е. Капаева // Иностранные языки в школе. - 2001. № 3. - C. $12-17$.

9. Коджаспирова, Г. М. Педагогика в схемах, таблицах и опорных конспектах [Текст] / Г. М. Коджаспирова. - М.: Айрис-пресс, 2007. - 256 с.

10. Листенгартен, В. C. Самостоятельная деятельность студентов: пособие для преподавателей вузов [Текст] / В. С. Листенгартен, С. М. Годник. - Воронеж: Изд-во Воронеж. ун-та, 1996. - 96 с.

11. Мильруд, Р. П. Самостоятельная работа как средство повышения обучаемости школьников [Текст] / Р. П. Мильруд // Вопросы интенсификации обучения иностранным языкам в школе. Самостоятельная работа школьников по иностранному языку. - 1987. - Вып. 4. C. $6-19$.

12. Миньяр-Белоручев, Р. К. Методический словник: Толковый словарь терминов методики обучения языку [Текст] / Р. К. Миньяр-Белоручев. - М.: Стелла, 1996. $143 \mathrm{c}$.

13. Соловова, Е. Н. Автономия учащихся как основа развития современного непрерывного образования личности [Текст] / Е. Н. Соловова // Иностранные языки в школе. - 2004. - № 3. - С. 41-44.

14. Dickinson, L. Self-instruction in Language Learning [Text] / L. Dickinson. - Cambridge: Cambridge University Press, 1987. - 200 p.
15. Holec, H. L'apprentissage auto-dirigé: une autre offre de formation [Text] / H. Holec // Le français dans le monde. Recherches et applications. Apprentissage et usage des langues dans le cadre européen. Juillet, 1998. - P. 213-256.

\section{References}

1. Bogoyavlenskaya, A. Ye. (2002). Pedagogicheskoye rukovodstvo samostoyatelnoi rabotoi i razvitiyem poznavatelnoi samostoyatelnosti studentov [Pedagogical guidance by independent work and development of cognitive independence of students]. Tver, Russia: Tver. gos. un-t, 106.

2. Graf, V., Ilyasov, I., lyaudis, I. I. (1981). Osnovi samoorganizatsii uchebnoi deyatelnosti i samostoyatelnaya rabota studentov [Bases of self-organization of educational activity and independent work of students]. Moscow, USSR: Izd-vo Mosc. Un-ta, 80.

3. Jukov, A. Ye., Simonenko, A. V. (2004). Organizatsiya samostoyatelnoi raboti studentov $\mathrm{v}$ visshei shkole. Didacticheskiye sredstva, tehnologii, programmi: monografiya [The organization of independent work of students at the higher school. Didactic means, technologies, programs]. Moscow, Russia: YuNITI-DANA, 220.

4. Zimnyaya, I. A. (2007) Pedagogicheskaya psihologiya: uchebnik dlya vuzov [Pedagogical psychology]. Moscow, Russia: Universiteyskaya kniga, Logos, 384.

5. Zmiyevskaya, N. P., Mirishnikova, O. G. (2008). Kontrol i samokontrol v sisteme uprajnenii po obucheniyu nauchnomu stilyu rechi inostrannih studentov na nachalnom etape [Control and self-control in the system of exercises on teaching to scientific style of the speech of foreign students at the initial stage]. Language, 13, 144-146.

6. Ilyin, Ye. P. (2000). Motivatsiya i motive [Motivation and motives]. Spb: Piter, 512.

7. Ivashchik, Ye. A. (1989). Samostoyatelnaya vneurochnaya uchebnaya rabota uchashchihsya kak sredstvo sovershenstvovaniya uchebno-vospitatelnogo protsessa po inostrannomu yaziku $\mathrm{v}$ srednei shkole (nem. yaz. 7 kl.) [Independent after-hour study of pupils as means of improvement of teaching and educational process on a foreign language at high school (German a language of $7 \mathrm{cl}$.)]. The Moscow State Pedagogical Lenin's Institute, 16.

8. Kapayeva, A. Ye. (2001). O formirovanii gotovnosti uchashchihsya k samoobucheniyu inostrannim yazikam [About formation of readiness of pupils for self-training to foreign languages]. Foreign languages at school, 3, 12-17.

9. Kodjaspirova, G. M. (2007). Pedagogika v shemah, tablitsah i opornih konspektah [Pedagogics in schemes, tables and basic abstracts]. Moscow, Russia: Airis-press, 256.

10. Listengarten, V. S., Godnik, S. M. (1996). Samostoyatelnaya deyatelnost studentov: posobiye dlya prepodavatelei vuzov [Independent activity of students]. Voronej, Russia: Izd-vo Voronej. un-ta, 96.

11. Milrud, R. P. (1987). Samostoyatelnaya rabota kak sredstvo povisheniya obuchayemosti shkolnikov [Independent work as means of increase of learning ability of school students]. Questions of an intensification of training to foreign languages at school. Independent work of school students on a foreign language, 4, 6-19.

12. Minyar-Beloruchev, R. K. (1996). Metodicheskii slovnik: Tolkovii slovar terminov metodiki obucheniya yaziku [Methodical dictionary: Explanatory dictionary of terms of methodology of the language teaching]. Moscow, Russia: Stella, 143.

13. Solovova, Ye. N. (2004). Avtonomiya uchashchihsya kak osnova razvitiya sovremennogo neprerivnogo obrazovaniya lichnosti [Autonomy of pupils as basis of development of modern continuous education of the personality]. Foreign languages at school, 3, 41-44. 
14. Dickinson, L. (1987). Self-instruction in Language Learning. Cambridge: Cambridge University Press, 200.

15. Holec, H. (1998). L'apprentissage auto-dirigé: une autre offre de formation. Le français dans le monde. Recherches et applications. Apprentissage et usage des langues dans le cadre européen. Juillet, 213-256.

Рекомендовано до публікації д-р пед. наук, професор Іваненко. В. К. Дата надходження рукопису 23.01.2015

Рощупкина Елена Анатольевна, кандидат педагогических наук, доцент, кафедра языковой подготовки Запорожский государственный медицинский университет, пр. Маяковского, 26, г. Запорожье, Украина, 69035

E-mail: cpklena@mail.ru

УДК 159.922.4:378.147-057.875-054.6-048.56

DOI: $10.15587 / 2313-8416.2015 .37396$

\title{
ЭТНОПСИХОЛОГИЧЕСКИЕ ОСОБЕННОСТИ ИНОСТРАННЫХ СТУДЕНТОВ И НАЦИОНАЛЬНЫЕ РАЗЛИЧИЯ ИХ ОБРАЗОВАТЕЛЬНЫХ СИСТЕМ
}

\author{
(C) Е. И. Гейченко, Л. И. Васецкая, В. Д. Хейлик \\ В статье описываются стратегии гармонизации довузовского когнитивного учебного опьта \\ иностранцев и лингводидактических технологий формирования коммуникативной компетенции в \\ условиях обучения языку в полинациональных группах в украинских вузах нефилологического профиля на \\ основе национально ориентированного подхода. Выделяются некоторые проблемы социокультурной \\ адаптации и роль в их нивелировании эффективных приёмов отработки речевых навыков и умений \\ Ключевые слова: региональные, культурные и ментальные особенности, альтернативные \\ технологические решения, этнопедагогика
}

The article deals with the issue of harmonization of pre-university cognitive experience of foreigners and linguodidactic technologies of communicative competence formations in the language learning in multinational groups in Ukrainian non-linguistic universities on the basis of nationally oriented approach. Some problems of social and cultural adaptation and role of effective methods of speech skills in their elimination are revealed

Keywords: regional, cultural and mental features, alternative technological solutions, ethnopedagogics

\section{1. Введение}

Современный учебный процесс убеждает в необходимости перехода от единообразия, излишней стандартизации образования, ведущего к консерватизму и схематизму, к многообразию, дифференциации и индивидуализации обучения.

Дифференцированное обучение русскому языку как иностранному может организовываться, во-первых, в зависимости от степени различий в содержании обучения (профилированное, вариатив ное, индивидуализированное) и, во-вторых, в зависимости от психологических особенностей обучаемых (интересов и склонностей, способностей и возможностей, индивидуальных качеств). Безусловно, эти два способа взаимопересекаются.

Опыт работы с иностранными студентами различных национальностей свидетельствует, что в методике преподавания РКИ должны учитываться их национальные (региональные, культурные, ментальные) психологические особенности, поскольку успешность или замедление процесса формирования навыков и умений всех видов речевой деятельности на иностранном языке напрямую зависит от уровня их сформированности на родном (или первом иностранном) языке и определяется индивидуальносубъективными сторонами процесса усвоения/овладения языковой и коммуникативной компетенциями, a также от влияния особенных и устойчивых национальных различий в системе образования.

Поэтому задача языковых кафедр представление иностранцам возможных альтернативных технологических решений в обучении всем видам речевой деятельности (ВРД), опирающихся на разные конструкты этого феномена как процесса.

Формирование у иностранных учащихся коммуникативной компетенции предполагает использование таких технологий обучения, которые обеспечивали бы моделирование процессов плодотворного аудиторного общения. Современная педагогическая стратегия, базирующаяся на коммуникативноличностном подходе, характери-зуется повышенным вниманием к таким актуальным проблемам, как гуманизация обучения, этнопеда-гогизация учебного процесса на основе исполь-зования национальнокультурных и социально-психологических особенностей иностранцев.

\section{2. Анализ литературных данных}

Вопросы использования особенностей этнокультурного фона в образовательном процессе рассматривались в работах М. Н. Вятютнева, О. Д. Митрофановой, Д. Дэвидсона, Е. И. Пассова, И. Е. Бобрышевой, А. В. Друзя, Н. Б. Крыловой, А. В. Рябоконя, В. Б. Манджиевой, Г. А. Палаткиной и др. 